\title{
Pendampingan dalam Pengelolaan Informasi POC Fermentasi Urine Kelinci
}

\author{
Heppy Purbasari ${ }^{\mathrm{a}, 1,{ }^{*}}$, Ilham Rochad Saputra ${ }^{\mathrm{b}, 2}$, Mahardhika Yusack Effendi ${ }^{\mathrm{b}, 3}$ \\ a,b, Universitas Muhammadiyah Surakarta, Jl. A Yani Pabelan, Kartasura, Sukoharjo, 57162 \\ ${ }^{1}$ heppy.purbasari@ums.ac.id* \\ * corresponding author
}

ARTICLE INFO

Article History

Received,14-11-2020

Revised,12-01-2021

Accepted,21-01-2021

Keywords

Laboratory Test;

POC Rabbit Urine

Fermentation

\begin{abstract}
This service is a continuation of his previous service, namely making labels and brands for Liquid Organic Fertilizer (POC) Rabbit Urine Fermentation and AB Mix Nutirsi at Mama Hidproponics UMKM. Labels are an effective way of marketing because they contain information that consumers need. Information that can be given to provide satisfaction to consumers, then Mama Hidproponik hopes to make information about the POC content of Rabbit Urine Fermentation by conducting laboratory testing of the quality of goods. Based on the results of laboratory tests that have been carried out, the results show that Rabbit Urine Fermentation POC has good content and is not dangerous.
\end{abstract}

\section{PENDAHULUAN}

Kegiatan pertanian merupakan salah satu sumber Pendapatan Asli Daerah untuk meningkatkan pendapatan suatu daerah Kabupaten/Kota. Berdasarkan Peraturan Pemerintah No 12 tahun 2019 tentang Pengelolaan Keuangan Daerah Pendapatan Asli Daerah terbagi dalam 3 jenis yaitu pajak daerah, retribusi daerah, hasil pengelolaan kekayaan daerah yang dipisahkan dan lainlain PAD yang sah (PeraturanPemerintahNo12, 2019). Kegiatan agrobisnis dan agribisnis dapat membantu petani meningkatkan pendapatan dan mengurangi pengangguran sehingga perekonomian dapat tumbuh dengan baik (Syahza, 2003).

Pemasaran merupakan konsep yang penting dalam perdagangan. Salah satu kegiatan pemasaran, seorang penjual harus dapat menjelaskan secara detail atas produk-produk yang dijual. Penjelasan tentang produk-produk yang dijual dapat dinformasikan secara langsung oleh penjual maupun secara tertulis dalam kemasan produk tersebut. Dalam teori pemasaran dikenal istilah IMC atau integrated marketing communication dimana IMC penekankan kepada pemberian nilai tambah atas suatu produk dan mengevaluasi komunikasi yang berupa iklan, promosi secara langsung, penjualan, dan hubungan dengan masyarakat (Nuranindya, 2012).

Label suatu barang memiliki beberapa informasi, misalnya seperti ukuran netto suatu produk, ingredient atau kandungan produk, cara penggunaan, masa kadaluarsa dan lain sebagainya. Sesuai dengan penelitian (Cahyadi, 2014) menyampaikan bahwa private brand strategi yang terdiri dari kualitas produk, harga, presentasi dan promosi air mineral $600 \mathrm{ml}$ merek alfamart dapat meningkatkan brand loyalty atas produk tersebut. Untuk memenuhi kebutuhan yang diinginkan konsumen Mama Hidroponik berusaha membuat informasi tersebut dengan melakukan pengujian laboratorium kandungan nutrisi Pupuk Organik Cair (POC) dari urine kelinci dan AB Mix. Tetapi karena dalam melakukan pengujian tersebut dibutuhkan biaya yang banyak, maka Mama Hidroponik belum dapat melakukan uji laboratorium tersebut.

POC Fermentasi Urine Kelinci dibuat dengan menggunakan bahan dasar Urine Kelinci yang kemudian dilakukan fermentasi. Proses fermentasi berlangsung selama 28-30 hari. Selama proses fermentasi, penutup drum yang berisi urine kelinci dalam proses fermentasi harus dibuka setiap seminggu sekali, hal ini dilakukan agar gas yang dihasilkan dalam proses fermentasi dalam drum tidak meledak. 
Keberhasilan di bidang pertanian tidak dapat lepas dari intensifikasi yang ada. Keberhasilan intensifikasi dalam bidang pertanian yaitu adanya bibit unggul, penggunaan pupuk, penyuluhan, pengairan, pemeliharaan dan lain sebagainya. Tidak adanya subsidi pupuk dari pemerintah dan lonjakan harga pupuk menyebabkan petani kesulitan dalam mencari pupuk. Dengan adanya kondisi tersebut mulai banyak beredar pupuk hasil rekayasa teknologi yang mutu dan efektifitasnya belum di uji (Suriadikarta, 2004).

Banyaknya pupuk yang beredar maka konsumen dalam hal ini adalah petani harus berhatihati dalam memilih pupuk, dimana pupuk yang digunakan harus sesuai dengan unsur hara yang terdapat dalam label suatu produk. Untuk melindungi petani dari penggunaan pupuk maka perlu dilakukan pengawasan mutu dan uji efektifitas di lapangan (Suriadikarta, 2004).

Peraturan Menteri Pertanian No 70 tahun 2011 tentang Pupuk Organik, Pupuk Hayati dan Pembenahan Tanah mengatur bahwa pupuk organik merupakan pupuk yang berasal dari tumbuhan mati, kotoran hewan atau bagian hewan atau limbah organik lainnya yang telah melalui proses rekayasa yang berbentuk padat atau cair. Pupuk Organik Cair (POC) dibuat dengan cara melarutkan pupuk organik setengah jadi kedalam air. Pupuk organik yang dilarutkan berupa pupuk kandang, pupuk hijau, pupuk kompos dan campuran semuanya. Penggunaan POC jenis ini agar lebih efisien yaitu dengan cara disiramkan langsung pada tanah, bukan disemprotkan pada daun.

(Isnawan, 2015) menyatakan bahwa pemberian POC pada tanaman padi dapat meningkatkan pertumbuhan dan hasil tanaman padi yang lebih baik. Hal ini terjadi karena POC dapat merupakan zat-zat organik yang berada dalam sumber hara tanaman padi. (Marpuang, 2017) juga menyatakan bahwa penggunaan POC dapat meningkatkan pertumbuhan tanaman kobis. Dalam penelitian ini POC yang digunakan menggunakan Kriyu dan kotoran kelinci, dimana masing-masing komponen memberikan nilai tambah untuk tanaman kobis yaitu meningkatkan bobot tanaman dan besarnya diameter krop kobis.

Mama Hidroponik merupakan bagian dari Mama Agribusiness and Wholesale di daerah Sukoharjo. Mama Hidroponik beralamat di Jati Trobayan Rt 3 Rw 8 Mulur, Bendosari, Sukoharjo. Mama Hidroponik mulai membuat dan menjual POC Fermentasi Urine Kelinci mulai pada bulan September 2018. Selama ini pemasaran yang dilakukan baru oleh Mama Hidroponik adalah di hari minggu pada saat Car Free Day (CFD) di Jl. Slamet Riyadi Surakarta dengan berlokasi di depan Bank Mega, Surakarta. Di samping itu, proses pemasaran juga menggunakan media sosial (Social Media) berupa akun Facebook dan group Whatsapp yang dimiliki. Dengan meluasnya pola pemasaran dan semakin meningkatnya konsumen, dibutuhkan usaha lebih lanjut untuk untuk menarik minat konsumen dan kepercayaan konsumen terhadap suatu produk. Untuk itu produk yang dimiliki harus memberikan informasi yang dibutuhkan oleh konsumen agar tingkat kepercayaan konsumen meningkat terhadap produk yang dihasilkan oleh Mama Hidroponik. Terkait dengan informasi atas suatu produk, tentunya customer membutuhkan informasi atas suatu produk, dalam hal ini kandungan yang terdapat dalam POC Urine Kelinci.

Berdasarkan uraian di atas, permasalahan yang dihadapai Mama Hidroponik adalah bagaimanakah cara memberikan informasi kandungan POC Fermentasi Urine Kelinci kepada konsumen secara efektif?dibutuhkan pengujian laboratorium untuk produk POC Fermentasi Urine Kelinci guna memberikan kepercayaan kepada para konsumen terkait dengan kualitas produk yang dijual.

Untuk mengatasi permasalahan yang telah disebutkan sebelum maka kami melakukan pemecahan masalah sebagai berikut:

1. Melakukan uji kandungan POC di Laboratorium Kimia Tanah dan Kesuburan di Universitas Negeri Sebelas Maret Surakarta

2. Hasil uji laboratorium di cetak dalam Merk dan label POC Urine Kelinci

\section{PELAKSAAAN DAN METODE}

Kegiatan pengabdian masyarakat dilakukan selama 3 bulan, kegiatan ini diawali dengan persiapan bahan-bahan untuk pembuatan POC Fermentasi Urine Kelinci, yang kemudian tersebut dikirimkan Laboratoium Kimia Tanah dan Kesuburan di Universitas Sebelas Maret Surakarta. Proses pengujian ini dilakukan selama 1 minggu. Setelah adanya hasil uji laboratorium POC Fermentasi Urine Kelinci, hasil ini akan dipublikasikan melalui label produk yang telah di desain 
oleh tim pengabdian masyarakat beserta pemilik Mama Hidroponik. Label produk merupakan cara yang efektif untuk melakukan pemasaran, karena dalam label produk tersebut telah tercantum berbagai informasi yang berguna untuk konsumen.

Pembuatan desain label produk dilakukan selama 2 minggu, dalam pembuatan ini dilakukan sharing hal-hal yang tercantum dalam label produk. Setelah di setujui desain label produk, dan adanya hasil uji laboratotium maka langkah yang selanjutnya ditempuh adalah mencetak label produk POC Fermentasi Urine Kelinci.

\section{HASIL DAN PEMBAHASAN}

Kegiatan ini dilakukan dalam rangka memberikan informasi kepada konsumen tentang bahan yang terkandung dalam POC Fermentasi Urine Kelinci yang dibuat oleh Mama Hidroponik. Kegiatan ini dilaksanakan selama 3 bulan. Kegiatan dimulai tanggal 5 Oktober 2019, adapun kegiatan yang kami lakukan adalah:

1. Mendaftarkan hasil POC Fermentasi Urine Kelinci di Laboratorium

Produk POC Fermentasi Urine Kelinci yang telah jadi dikirimkan ke Laboratoium Kimia Tanah dan Kesuburan di Universitas Sebelas Maret Surakarta untuk dilakukan pengujian. Proses pengujian dilakukan selama 1 minggu. Hasil pengujian terhadap POC Fermentasi Urine Kelinci adalah sebagai berikut:

Tabel 1. Hasil Uji Laboratorium

\begin{tabular}{lll}
\hline No & Kode & Hasil \\
\hline 1 & N total & $0,48 \%$ \\
2 & P total & $404,80 \mathrm{ppm}$ \\
3 & K total & $0,98 \%$ \\
4 & C. Organik & $2,15 \%$ \\
5 & Bahan Organik & $3,72 \%$ \\
6 & C/N Ratio & 4,48 \\
7 & $\mathrm{pH}$ & 4,51 \\
\hline
\end{tabular}

Berdasarkan hasil laboratorium, POC Urine Kelinci memiliki kandungan Nitrogen 0,48\%; Fosfor 404,80 ppm; Kaliaum atau potasium 0,98\%; C-organik 2,15\%; Bahan organik 3,72\%; $\mathrm{C} / \mathrm{N}$ ration 4,48\%; $\mathrm{pH} 4,51$ yang berarti kandungan dalam POC Urine Kelinci sesuai dengan aturan yang tertuang dalam Peraturan Menteri Pertanian (Permentan) Nomor 70 tahun 2011 tentang Pupuk Organik, Pupuk Hayati dan Pembenah Tanah. Adapun syarat yang harus dipenuhi dalam pembuatan POC sesuai dengan (PERMENTAN70, 2011) 2011 adalah:

Tabel 2. Syarat Pembuatan POC

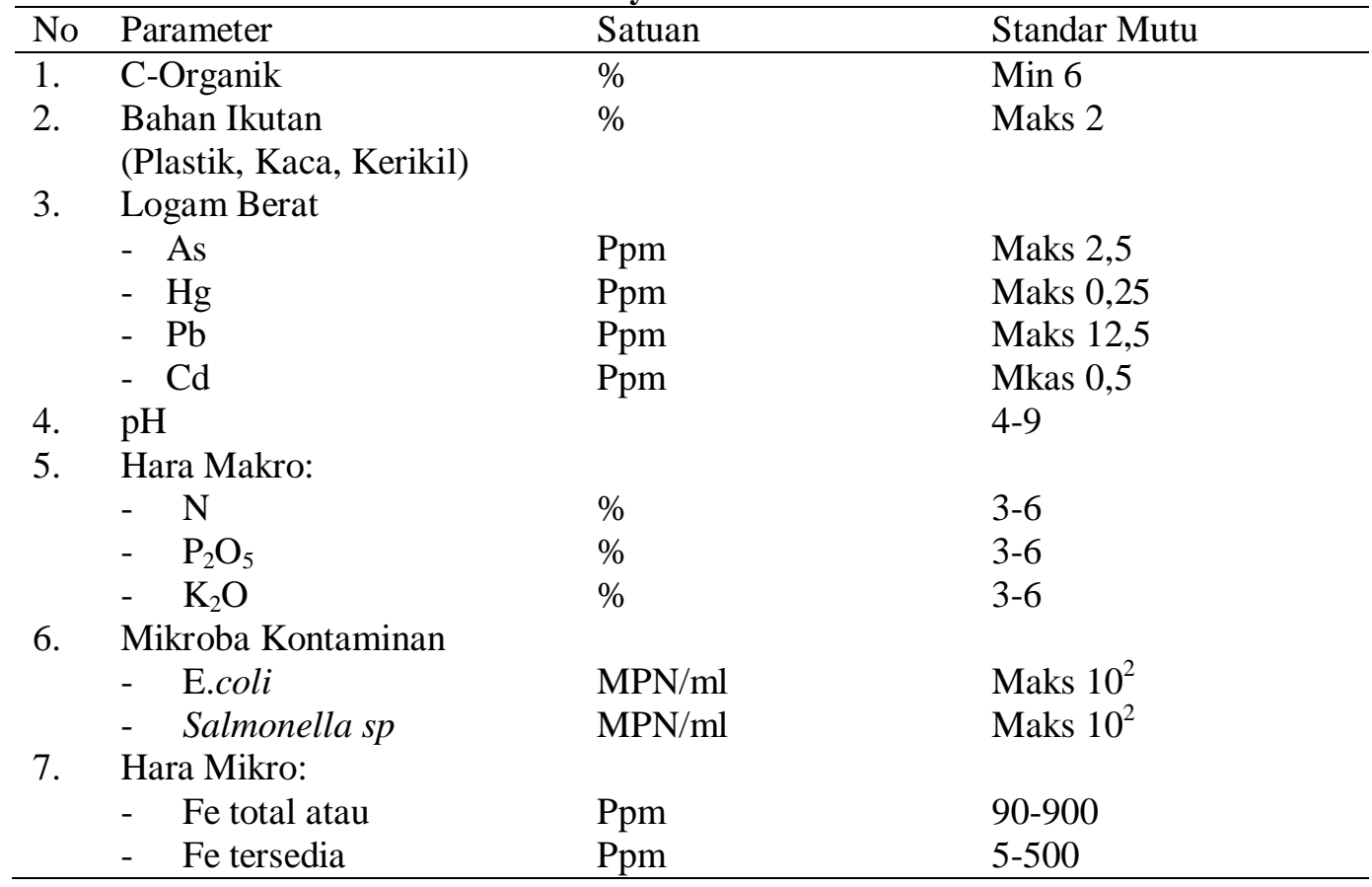




\begin{tabular}{lll}
\hline - Mn & Ppm & $250-5000$ \\
- & Pum & $250-5000$ \\
- Zn & Ppm & $250-5000$ \\
- B & Ppm & $125-2500$ \\
- Co & Ppm & $5-20$ \\
$\quad-$ Mo & Ppm & $2-10$ \\
8. Unsur Lain & & \\
$\quad-$ La & Ppm & 0 \\
- Ce & Ppm & 0 \\
\hline
\end{tabular}

Berdasarkan hasil pegujian laboratorium diketahui bahwa POC Urine Kelinci memiliki kandungan Nitrogen $0,48 \%$ yang berarti POC ini memiliki kandungan untuk memberikan pertumbuhan pada akar, batang, dan daun sekaligus untuk pembentukan klorofil, dimana klorofil merupakan bagian yang penting dalam proses fotosintesis. Forfor 404,80 ppm yang terkandung dalam POC urine kelinci berfungsi untuk mempercepat proses bunga, biji dan buah.

Selain itu POC urine kelinci mengandung Kalium atau potasium sebesar 0,98 \%, unsur ini diperlukan tanaman karena kalium merupakan unsur hara mikro yang diperlukan untuk penyerapan air dan membantu tanaman dalam pengedaran karbohidrat, mempercepat metabolisme tanaman dan mencegah gugurnya bunga dan buah. C-Organik dalam POC urine kelinci sebesar 2,15\% memiliki fungsi yang hampir sama dengan kalium yaitu untuk meningkatkan kesuburan tanah dan menyediakan micro hara dan faktor pertumbuhan lainnya yang biasanya tidak disediakan oleh pupuk kimia.

POC Urine kelinci juga mengandung bahan organik lainnya sebesar 3,72\%, dimana bahan organik ini berasal dari daun yang telah dilakukan proses pengomposan. Proses pengomposan dari bahan organik berfungsi untuk kesuburan fisik, kimia dan biologi tanah, meningkatkan mikroba untuk menyediakan unsur hara dan mikro dalam tanah. Selain itu POC urine kelinci juga mengandung $\mathrm{C} / \mathrm{N}$ ratio sebesar 4,48 , dimana fungsi $\mathrm{C} / \mathrm{N}$ ratio merupakan komponen yang dibutuhkan micro organik untuk menyeimbangkan antara carbon dan nitrogen dan $\mathrm{pH}$ yang terkandung dalam POC urine kelinci sebesar 4,51 yang berarti telah sesuai dengan aturan dari Permentan No 70 tahun 2011.

2. Hasil uji laboratorium di cetak dalam Merk dan label POC Urine Kelinci

Untuk memberikan informasi kepada konsumen mengenai kandungan POC Urine Kelinci, maka dengan adanya hasil uji laboratorium ini, Mama Hidroponik melampirkan hasil uji laboratorium dalam Merk dan label yang telah dimiliki. Adanya label produk dan informasi yang diberikan berdampak pada peningkatan penjualan POC Fermentasi Urine Kelinci Adapun hasil dari pembuatan Merk dan label tersebut adalah:

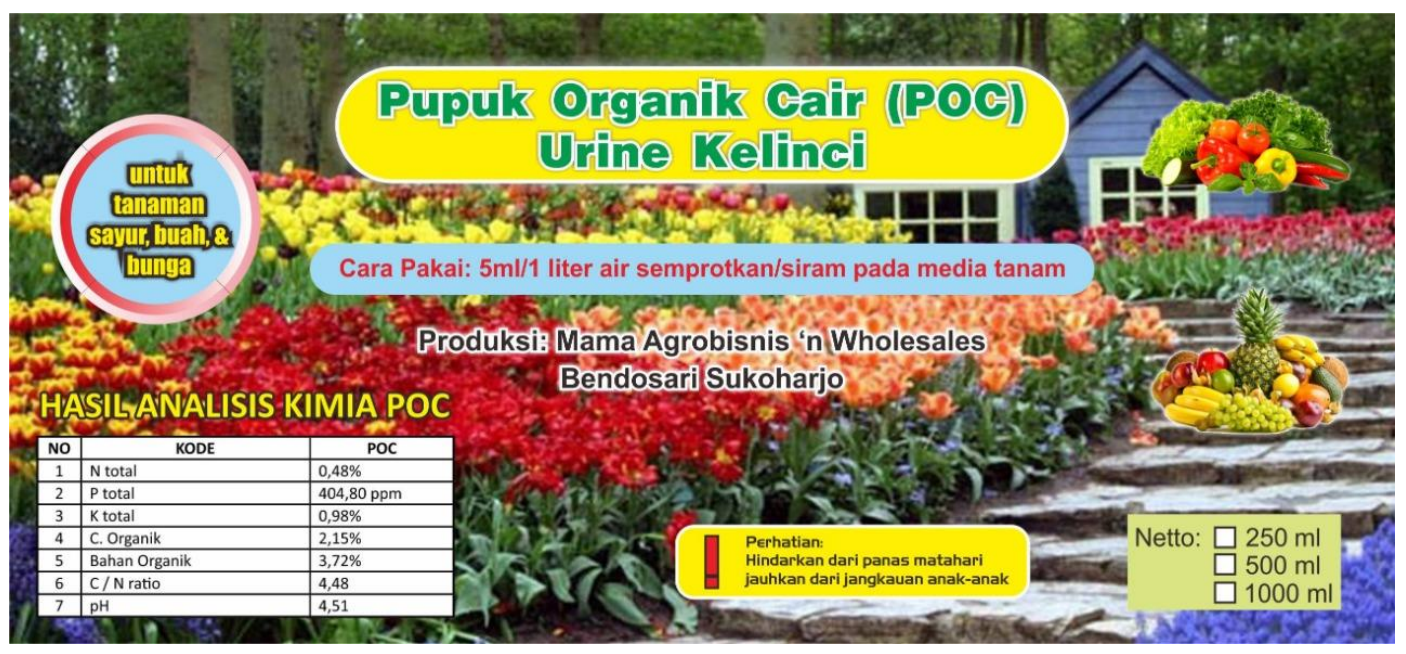

Gambar 1. Hasil Uji Laboratorium dalam Merk dan Label

\section{PENUTUP}

Heppy Purbasari et.al (Pendampingan Dalam Pengelolaan Informasi POC Fermentasi Urine Kelinci) 


\section{Simpulan}

Kegiatan pengabdian masyarakat yang dilakukan pada usaha pertanian Mama Hidroponik berlangsung selama 3 bulan. Permasalahan yang dialami Mama Hidroponik adalah belum adanya informasi yang dapat diterima konsumen secara efektif. Dengan adanya permasalahan tersebut Tim Pengabdian Masyarakat memberikan saran untuk melakukan uji laboratorium kandungan POC Fermentasi Urine Kelinci dan kemudian hasil tersebut dicantumkan dalam label produk POC Fermentasi Urine Kelinci. Dari hasil pengujian uji laboratorium diperoleh hasil bahwa POC Fermentasi Urine Kelinci memiliki komponen yang berada dalam batas aman, sehingga dapat digunakan pada segala macam tumbuhan.

\section{Saran}

Kegiatan pengabdian masyarakat telah berlangsung dengan baik, apabila ada tim pengabdian lain yang ingin mengembangkan pengabdian masyarakat ini, masih terdapat beberapa hal yang dapat dikembangkan misalnya seperti pengurangan gas dalam POC Fermentasi Urine Kelinci, pembuatan produk-produk pupuk dan lain sebagainya.

\section{Ucapan Terima Kasih}

Tim pengabdian masyarakat menyampaikan terima kasih kepada Universitas Muhammadiyah Surakarta yang telah membiayai pengabdian masyarakat sehingga dapat berlangsung dengan baik, dan kepada Mama Hidroponik yang telah bersedia bekerja sama dalam pelaksanaan pengabdian masyarakat ini.

\section{DAFTAR PUSTAKA}

Cahyadi. (2014). Pengaruh Privat Brand Strategi Terhadap Brand Loyalti Pada Air Mineral $600 \mathrm{ml}$ Merek Alfamart di Siwalankerto Surabaya. Jurnal Strategi Pemasaran Vol 2 no 1.

Isnawan. (2015). Pemakaian Pupuk Organik Cair Sebagai Dekomposer dan Sumber Hara Tanaman Padi (Oriza Sativa L). Planta Tropika Journal of Agro Science Vol 3 No 2, 94-99.

Marpuang. (2017). Pemanfaatan Jenis dan Dosis Pupuk Organik Cair (POC) Untuk Meningkatkan Pertumbuhan dan Hasil Sayuran Kubis . Jurnal Agroteknosains Vol 1 No 2, 117-123.

Nuranindya, D. (2012). Proses Pembentukan Brand Awareness dan Brand Image Melalui Penerapan Integrated Marketing Communication (IMC) Pada Produk Jasa Baru (Studi Kasus Solusi RUmah Holcim). Tessis. Universitas Indonesia.

PeraturanPemerintahNo12. (2019). Pengelolaan Keuangan Daerah .

PERMENTAN70. (2011). Pupuk Organik, Pupuk Hayati dan Pembenah Tanah.

Suriadikarta, e. a. (2004). Petunjuk Teknis: Uji Mutu dan Efektifitas Pupuk Alternatif Anorganik.

Syahza, A. (2003). Paradigma Baru: Pemasaran Produk Pertanian Berbasis Agribisnis di Daerah Riau. Jurnal Ekonomi TH VIII, 1-11. 